\title{
FY2020 May Monthly Status Report for the VTR
}

\author{
Jordi Roglans-Ribas \\ June 2020
}

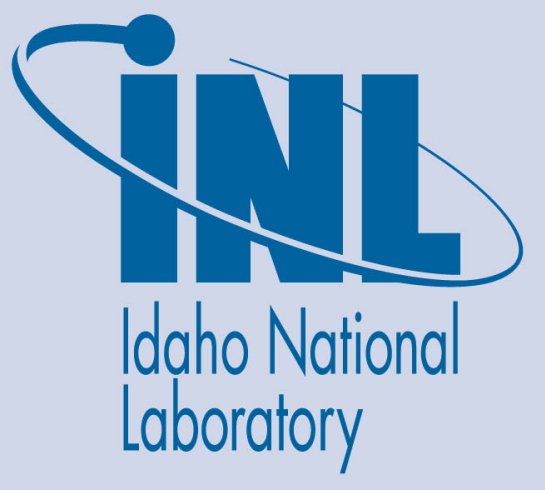

The INL is a U.S. Department of Energy National Laboratory operated by Battelle Energy Alliance 


\title{
FY2020 May Monthly Status Report for the VTR
}

\author{
Jordi Roglans-Ribas
}

June 2020

\section{Idaho National Laboratory Idaho Falls, Idaho 83415}

http://www.inl.gov

$$
\text { Prepared for the }
$$

U.S. Department of Energy

Under DOE Idaho Operations Office

Contract DE-AC07-05ID14517 


\section{Mark Arenaz, Federal Project Director}

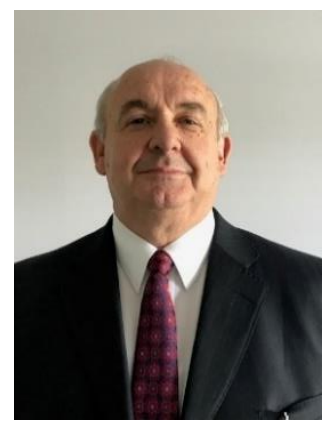

May was an interesting month for the VTR Project. All Critical Decision (CD)-1 documentation was ready and approved to the extent possible and presentation material was prepared for a Project Management Risk Committee (PMRC) meeting in May. Due to some identified concerns from other Programs within the Department, we agreed to a two-week delay for the CD-1 PMRC presentation which pushed the meeting out until June 2, 2020. We still have high expectations that the PMRC will endorse approval of the CD-1 to the Energy Systems Acquisition Advisory Board (ESAAB). After approval, we will transition from the Initiation phase to the Execution phase of the project. Things do not get any easier and the proposed schedule to get us to CD-2/3 and CD-3A is aggressive. However, the project has demonstrated a commitment and professionalism par none to date and we will move forward sharply.

\section{Jordi Roglans-Ribas, Program Overview}

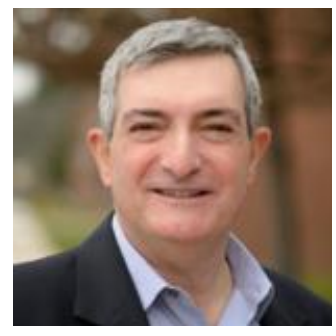

CD-1 documentation, such as the Acquisition Plan and the Preliminary Project Execution Plan (PPEP), was revised to incorporate Project Peer Review (PPR) and Independent Cost Review (ICR) comments and these documents have been submitted to U.S. Department of Energy (DOE)-Headquarters for approval. The Department of Energy Office of Project Management (OPM) ICR report was issued in final form and recommended proceeding to CD-1 approval. Questions regarding fuel source materials were addressed through multiple meetings between the DOE Office of Nuclear Energy (DOE-NE) and the National Nuclear Security Administration (NNSA). In preparation for initiating the Execution phase of the project, organizational staffing plans are under development to hire needed staff as we enter the preliminary design phase.

The first-ever virtual American Nuclear Society (ANS) meeting will be held June 8-11 and Kemal Pasamehmetoglu will participate in the Advanced Reactor Panel on June 10. The focus of this panel session is to discuss the challenges and opportunities for the U.S. to share the benefits of clear, secure, reliable power with the world. Kemal will join representatives from X-energy, TerraPower, the Nuclear Reactor Innovation Center (NRIC), and Venrock. Also a first, a sponsorship code was provided to enable all VTR staff and other industry and university collaborators to participate in the conference.

Idaho National Laboratory (INL) senior staff worked closely the with DOE Idaho Operations Office (DOE-ID) to enable an expedited review of Environmental Impact Statement (EIS) documents, as well as assisting with developing, maintaining, and statusing the project schedule. Finally, subcontract proposals for the design-build contract were received and are being reviewed by the source evaluation board. Award of the contract is anticipated in mid-September.

\section{Pat Schweiger, Reactor Technical Integration}

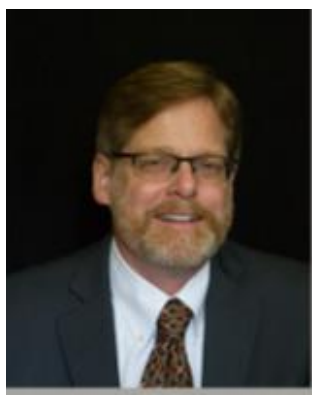

The following activities were supported during the month of May.

General Electric-Hitachi (GEH)/Battelle National Incorporated (BNI) Design Engineering Support

Continued supply chain investigations for equipment that requires prototyping, including the reactor vessel, in vessel transfer machine (IVTM), intermediate heat exchanger (IHX), sodium to air heat exchanger (SAHX), electromagnetic pump (EMP), and control rod drive mechanism (CRDM). Continued researching additional information regarding 
manufacturing to support ongoing refinement of the VTR cost estimate. This activity is expected to continue through the end of Fiscal Year (FY) 2020.

Held a 90\% review of the B24 Optioneering Report and identified areas for improvement before the June review with Battelle Energy Alliance (BEA).

Provided the Fuel Outage Operations Approach document to GEH. Issued the VTR Fault List Development document and the VTR IHX Seal Plate Design Specification and Drawing. Prepared four Strategic Thermal Irradiations Capability (STIC) for the first AVEVA 3D model review.

Continued building linkages between the stakeholder and system-level requirements. The purpose of refining requirements building linkages is to prepare the project for preliminary design work and to enable rapid impact analysis of any future design or requirements changes on the existing design effort.

\section{TerraPower Support}

Drafted the test assembly fabrication plan for core component mechanical tests and transmitted to the INL and Argonne National Laboratory (ANL) for review.

Suspended the Cs sequestration test due to COVID-19 restrictions. Full-Size Assembly Structural Testing Tower (FASTT) modification equipment and Test Assembly Handling Machine (TAHM) grapple were delivered by suppliers. Installation work is also delayed due to the COVID-19.

\section{FFTF Documentation and Data Recovery}

Requested information on the floor valves used during the operation of the Fast Flux Test Facility (FFTF). The floor valve is essentially an air lock that seals while allowing the transfer of fuel and test assemblies through transfer ports from the refueling machines while maintaining an argon atmosphere and proper shielding. Provided the FFTF System Design Description, SDD 41-7, for the floor valve. Began a search to obtain a list of all floor valve drawings.

Located and retrieved 92 drawings for the design of the control rods and absorber assemblies for the FFTF. These drawings will be reviewed for export control information and sent through Information release as soon as access is available to the Lab.

\section{VTR Control Rod Mechanical Design Analysis}

Developing a design support document to complement the three computer codes used to perform the mechanical design of absorber assemblies. The design support document describes the purpose and basic functions of the three codes, the essential input data required by them, and the mechanical life-limiting characteristics which they calculate and the means by which they are calculated. This design support document will contain the essential information necessary to effectively run the computer codes for the mechanical design of an absorber assembly.

\section{Calculation Support for VTR Waste Form Analysis}

Identified an initial concept for the waste form and design requirements for storage and transportation. Developed and submitted a draft description document for a VTR dry fuel storage design to BEA for review. Staff continued work on the design concept and an initial thermal model for the VTR spent fuel storage cask. A preliminary evaluation will be compiled and sent to INL for comment and modifications by the end of May or early June. 


\section{Tom Fanning, Nuclear Technical Integration}

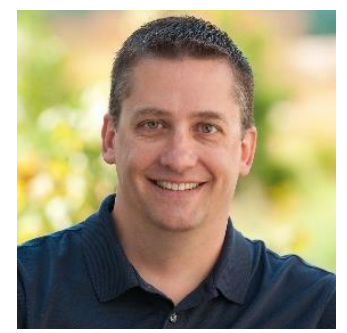

\section{Fuel}

Completed and approved the VTR Fuel Performance Design Basis, Rev. 1 for release in early June. This revision provides justification for applying the U-10Zr database and experience to the $\mathrm{U}-20 \mathrm{Pu}-10 \mathrm{Zr}$ fuel used in the VTR. Incorporated the current prognosis for the use of U-Pu-Zr-Ga into Rev. 1 but will be updated in later revisions as more information becomes available.

Clarified the scope for the advanced conceptual design of VTR Pu feedstock processing (specifically, Am removal and oxide reduction of European-sourced $\mathrm{Pu}$ ) to limit facility layouts to existing buildings at the Savannah River Site (SRS), with any INL-based implementation deferred to later, if needed. Considered and summarized additional aspects of using U.S. excess weapons Pu in VTR fuel production to support CD-1 deliberations.

Continued advanced conceptual design for several fuel processing gloveboxes and associated equipment. Issued Functional and Operational Requirements (FOR) reports for the casting system, heel characterization, and demolding equipment and process. Completed drafts for the heel breaking equipment and process and the slug processing glovebox. Started drafts for the quality assurance (QA) equipment and glovebox. Issued Technical Evaluation (TEV) reports for the casting furnace advanced conceptual design and the fuel slug demolding equipment and process, and several others are currently in process. These reports describe the equipment and process, include equipment models and layouts, describe risks and recommendations, and gather historical fuel manufacturing information that is being leveraged in VTR designs and are intended to support equipment procurements as well as development of a detailed prototyping and test planning. Issued and received initial feedback for a Request for Information (RFI) for precision bore glass tubes for fuel slug casting. The manufacturing facility used for these critical components during historical fuel manufacturing campaigns no longer exists and VTR seeks to evaluate options to reestablish such a capability or identify alternatives.

INL and Savannah River National Laboratory (SRNL) personnel continued to collaborate to evaluate options for VTR fuel fabrication at either location or various combinations thereof, focusing on the comparative advantages and disadvantages with those locations as well as the associated technical risks and cost impacts. Identified viable options at both sites and the team continues to provide information to support an eventual DOE decision on the fuel manufacturing location(s).

Drafted and transmitted a test assembly fabrication plan for core component mechanical tests for review. Provided written responses for all questions from HT9 suppliers. One supplier provided responses and budgetary quotes for both HT9 starting material and cladding supply, including production process development and qualification as the first step before actual volume production. Other supplier responses are delayed due to COVID-19 impacts. The draft procurement strategy and supplier qualification document for HT9 starting material, duct, and cladding supply is written and undergoing internal review at TerraPower. Continued work on the rod-loading and subassembly assembly stations with minor modifications and improvements on draft process flow and descriptions, concepts, and requirements document. Drafted division of responsibility DOR documents for the fuel production stations.

Continued application of BISON to metal fuel, with tasks addressing a preliminary fuel performance assessment and parallel effort to benchmark BISON U-Pu-Zr fuel rod models against legacy data. Continued documentation of the preliminary fuel performance assessment for normal and off-normal operations. Provided resolution of comments to Oak Ridge National Laboratory (ORNL). Continued benchmarking of BISON ternary fuel models 
against data from the Experimental Breeder Reactor (EBR)-II X430 and FFTF Integral Fast Reactor (IFR)-1 irradiation tests. Completed an initial sensitivity analysis for the IFR-1 benchmark problem. BISON results appear to be very sensitive to coolant inlet temperature, coolant flow rate, and power level. Uncertainties in material properties such as the anisotropic swelling factor, fuel/cladding friction coefficient, and the thermal conductivity of the sodium bond do not have large effects on output parameters being monitored.

\section{Core Design}

Performed the first set of calculations on air activation in the Reactor Vessel Auxiliary Cooling System (RVACS) and identified unexpected levels of S-37 activity. This result was linked to an error in the database provided with the ORIGEN2 code. Once corrected, the air activity levels obtained in the RVACS are consistent with previous experience. Documented this finding. Future activation analyses will be based on a VTR-specific nuclear database that will be developed in the coming months.

Prepared and reviewed the work control document for construction of the PELICAN (pressure drop measurement) loop (see Figure 1). Identified three items that will need adjustment. Completed all external procurements and components have been received, except for the custom-made pump which should be delivered in the coming weeks. Custom piping work will be performed by the Argonne Central Shop.

Determined the range of power expected in each assembly for the core at equilibrium (as described in ECAR-4647). These results will be used to inform the range of flow rates needed in each assembly. Performed this assessment with and without used fuel in the shield region. Current results indicate that the power variation in any fuel location is less than $10 \%$ at equilibrium. For the nonfuel assemblies, the anticipated power variation can be up to $20 \%$. Locations potentially used for fuel storage will see a much larger relative variation, which is consistent with expectations. Inclusion of startup conditions, as part of continuing work, will impact those results.

\section{Safety Analysis}

Performed additional safety analyses to support the development of design requirements. New work includes simulations for primary and secondary pump overspeed (over-cooling) cases with various

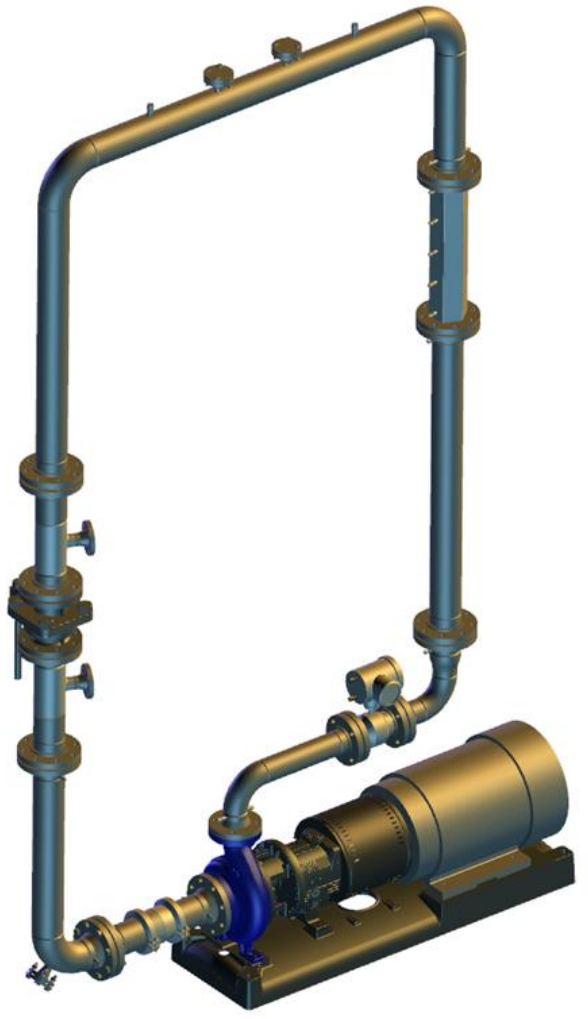

Figure 1. PELICAN loop for pressure drop measurement within a VTR assembly boundary condition assumptions. Performed an assessment on the impact of the RVACS inlet and outlet stack diameters on selected transient scenarios to support ongoing design activities.

The VTR Inventor model is being used to verify the primary system geometry and to identify where updates are needed to the current SAS model. Completed preliminary investigations for the system elevations, pump flow path geometry, and pool volumes, with modeling and model documentation updates to follow in June.

Initiated a new analysis activity which targets more accurate modeling of thermal stratification in the hot pool during protected loss-of-flow events. SAS can be coupled with external computational fluid dynamics (CFD) 


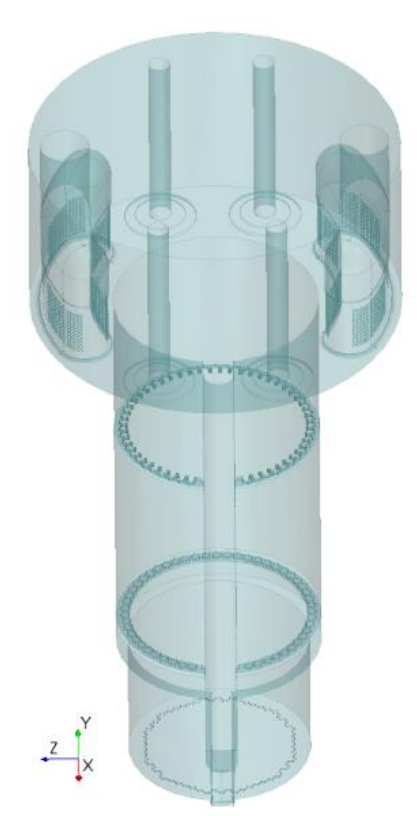

Figure 2. CFD model of the hot pool

models, which will be used to represent the VTR outlet plenum. Creating a CFD model of the hot pool (see Figure 2) based on the VTR Inventor model. Some simplifications to the geometry are being made to facilitate the initial coupling efforts.

\section{Safety Analysis Software Quality Assurance (QA) Activities}

The RVACS and SAS Software Requirements ECARs have undergone several technical reviews and are undergoing the final approval process.

Completed thermal calculations supporting control rod driveline (CRDL) reactivity feedback verification and have conducted a preliminary technical review. This work is the initial component of the planned SAS Reactivity Feedback ECAR. The radial expansion model used to support reactivity feedback calculations is also undergoing verification \& validation $(\mathrm{V} \& \mathrm{~V})$. Given the similarity of the core restraint design between VTR and FFTF, input data which supports validation of FFTF-specific models has been recovered and a preliminary detailed radial expansion model has been constructed and is undergoing debugging. Constructing a simplified radial expansion model using model independent data to verify additional features of the simplified expansion model that characterize the isolated effects of above-core load pad or grid plate expansion.

Continued development of a SAS model of the MCTF experiments. Constructed a simple core-only model which is being verified with respect to heat generation and heat transfer from the heated region to the primary coolant. Constructed the remainder of the primary system model which is undergoing verification to confirm appropriate heat transfer and flow dynamic characteristics. In the future, this model will be used to support validation of the natural circulation capabilities of SAS and provide some evaluation of the pool stratification model against experimental data.

Continued software V\&V efforts for the sodium fire analysis codes SOFIRE-II and NACOM. Conducted reviews of available reports to determine which experimental tests, if any, could be utilized for validation. The review focused on the F-Series and ABCOVE tests conducted at the Hanford Engineering Department Laboratory (HEDL). Performed simulations of the ABCOVE test AB1 using SOFIRE-II and ABCOVE tests AB5 and AB6 were performed using NACOM. Drafted preliminary reports which document comparisons between the simulations and experimental results for each test. Investigated sodium burning rates for F-Series tests F2 and F5 and a preliminary report was written to document the investigation.

\section{Safety Basis and PRA}

Continued V\&V activities for the Simplified Radionuclide Transport (SRT) code Version 2.0, which is being used for mechanistic source term calculations. Updated verification test problems for each function in the code and updated the Requirements Verification report. Model validation test cases are under construction, starting with the aerosol deposition models. Compared code results to more than 20 experiments on sodium aerosol deposition. Results will be documented in the Model Validation report.

Began preparations for the preliminary detailed success criteria and mechanistic source term analyses that will be conducted to comprehensively explore the impact of uncertainties. These analyses are important to accurately assess the reliability of passive safety systems and to properly account for radionuclide transport and retention phenomena. The results of the analyses, which will be performed later in this FY, will be used to update the probabilistic research analysis (PRA) and derive system requirements. 


\section{Kevan Weaver, Experiments Technical Integration}

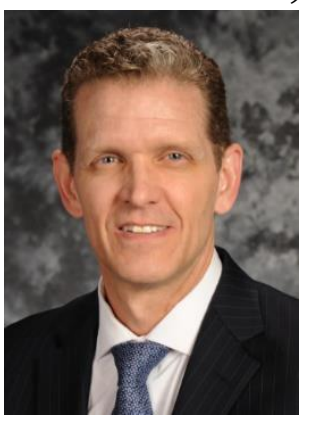

The Experiments Team within the VTR program includes nine "functional" areas aligned with the experiment vehicle types, along with related capabilities and initiatives, anticipated to be utilized within the VTR. Each area is led by a national laboratory technical expert and is supported by other national laboratory personnel, university partners, and industry partners. These areas will be realigned with the upcoming Design Decision (DD) Document that outlines new nomenclature for the experiment vehicles. This will better align with the project as it moves toward preliminary design.

Selected key accomplishments within specific functional areas are included below.

\section{Sodium Loop Capability Development}

Technical Lead: Mitch Farmer, ANL

Partners: University of Wisconsin, Purdue, Framatome

- Stopped work during operational testing of a proposed sodium fast reactor (SFR) cartridge impeller design in a small PVC water loop in Building 206. Work will continue after receiving approval to restart.

- Worked with SFR industry and university partners to develop a presentation for the VTR integration meeting scheduled for June 2-3.

- Receipt of shaft torque measurements for the cartridge loop pump has been delayed. A prototype design using a 50\% design margin on torque (as well as magnet strength) over that expected at a conservative operating temperature of $550^{\circ} \mathrm{C}$ will be developed. Completed the design and ordered magnet material ( $\mathrm{SmCo}$ ) so a prototype can be fabricated for testing at room temperature and then at expected operating temperatures.

- Continued efforts to get the cartridge transient analysis tool CARLITA through the software licensing process including an export control review. Framatome requested a copy of this software to support their work.

\section{Lead/Lead Bismuth Loop Capability Development \\ Technical Lead: Cetin Unal, LANL \\ Partners: University of New Mexico, Westinghouse}

Develop a Pre-Conceptual Design for a $\mathrm{Pb} / \mathrm{Pb}$-Bi Reactor Cartridge Test Loop. Design continues using the optimized mechanical pump design and will including updated computer-aided design (CAD) drawings for the $\mathrm{Pb}$-loop. TRACE- $\mathrm{Pb}$ modeling continued for safety calculations using the updated design parameters

Design and Testing of Centrifugal Pump for a Lead Cartridge Loop. Continued pump design and analysis for the two mechanical pump options. One option is undergoing design optimization with computational software in ANSYS; the other is based on commercial pump design, resized to the cartridge dimensions, and an increased number of blades. Both options will be printed and tested in water. Completed the water test loop design which will be sent out for fabrication bids. The variable speed pump drive motor, and related instrumentation, selected and ordered.

Irradiation Data Needs and Lead Cartridge Requirements and Interfaces. Continued development of requirements. Started technology readiness assessment of the materials envisioned for the lead cartridge.

Technology Readiness Assessment and Gap Analysis of Instrumentation for Monitoring Lead Cartridge Performance. Compiling information to identify the technology readiness level (TRL) of each variable to be 


\section{FY2020 May Status}

\section{Versatile Test Reactor}

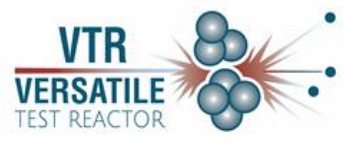

measured and to suggest research and development $(R \& D)$ where necessary. The final report will contain detailed sections summarizing each variable to be measured and discusses the current state of the technology.

Pump Optioneering Study for the VTR Pb Cartridge. Evaluated the following pump options: centrifugal pump, annular linear induction pump, conduction EMP, and gas lift pump.

Corrosion and Erosion Studies of Selected Clad and Structural Materials. Inserted 32 specimens into four sample holders. Extended testing by one month due to remote operation

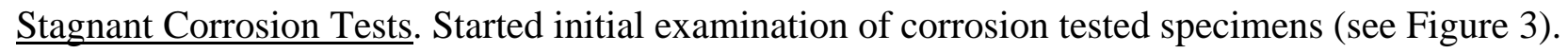
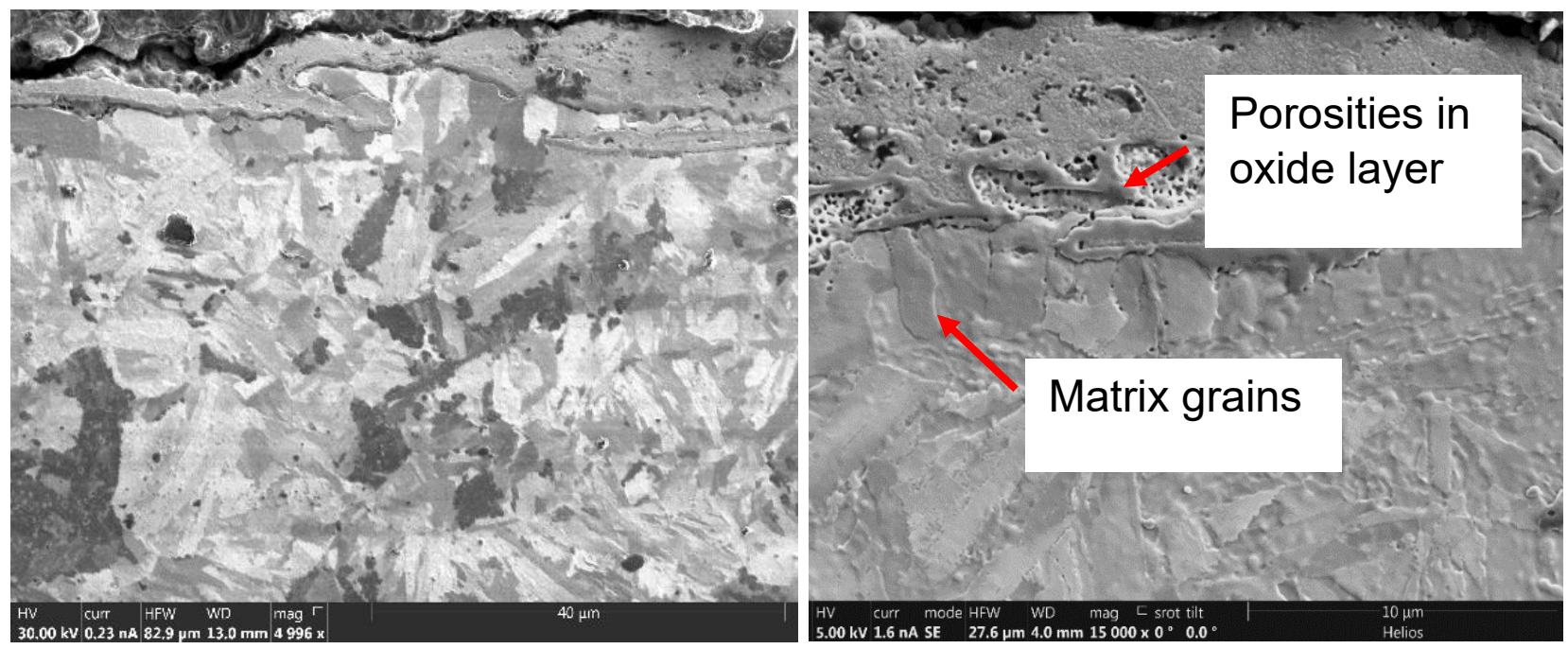

Figure 3. Cross sectional SEM/FIB images of HT9 specimen after 1-month exposure to Pb shows oxide scale.

Miniature MHD and Gas Lift Pumps for the Lead Cartridge Loop. Continued optimizing the design of pumping options to attain higher flow velocity in the 3-fuel rod bundle in the VTR Pb cartridge loop.

\section{Molten Salt Loop Capability Development}

Technical Lead: Joel McDuffee, ORNL

\section{Partners: University of Utah, University of Idaho, MIT, TerraPower}

Thermosyphon Test Loop (annular flow characterization). Continued internal review of journal paper "Singlephase, natural circulation annular flow measurements for cartridge loop irradiation experiments." This paper provides critical experimental data for validation of thermal hydraulics models of natural circulation flow in annular geometries representative of expected VTR cartridge experiments. Non-dimensional analyses indicate that natural circulation flow can provide liquid salt Reynolds numbers similar to those of some molten salt reactor concepts at relevant power densities. 
Corrosion Sensor Development. Fabricated parts for the miniaturized corrosion sensor that will use a fiber fused in glass to eliminate concerns regarding differential thermal expansion (see Figure 4). Journal paper "Metalembedded fiber optic sensor packaging and signal demodulation scheme towards high-frequency dynamic measurements in harsh environments" has been accepted and is now viewable online as a pre-proof: https://doi.org/10.1016/j.sna.2020.112075.

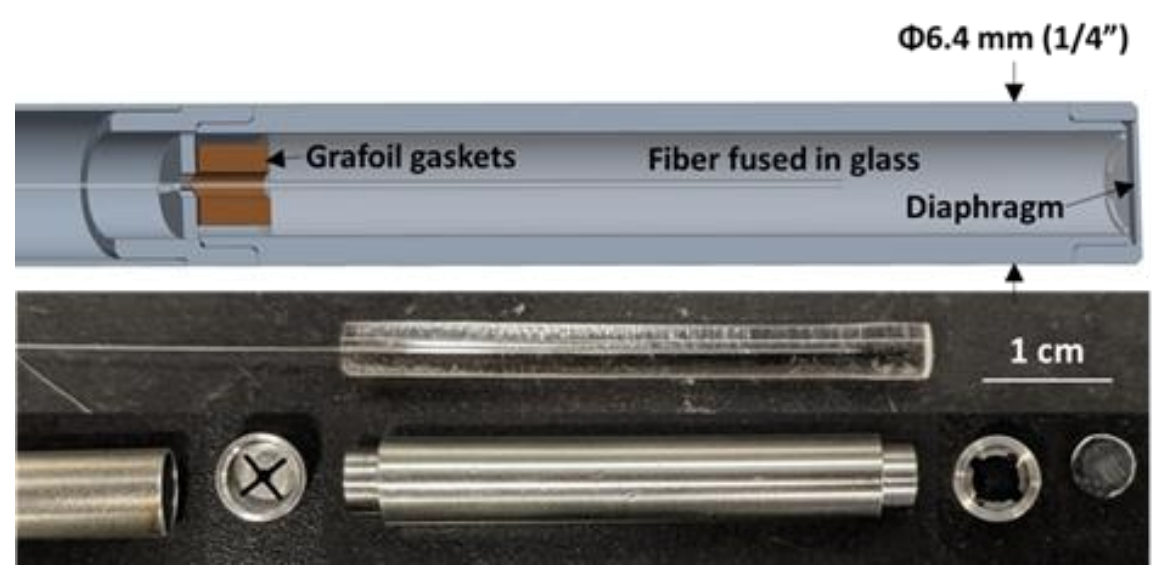

Figure 4. Miniature corrosion sensor.

\section{Gas Loop Capability Development}

Technical Lead: Piyush Sabharwall, INL

\section{Partners: Texas A\&M, University of Michigan, General Atomics}

Development of Innovative Measurement Techniques for Fission Product Transport Quantification. Submitted the final version of Year-1 report, which is now publicly available. Continued scaling analysis.

Development of an Integrated Multi-functional Experimental Vehicle for GFR Irradiation Testing in VTR. Insitu thermal property measurement system is under construction. Delayed volumetric fiber optic temperature monitoring for heat exchanger design and fabrication and analysis of baseline thermal performance.

Surface Emissivity Measurements. Initiated shakedown tests of the test chamber and Solid Works model is almost complete.

Laser-Based Primary Coolant Impurity Measurements. Developed a preliminary simulation to predict the emission spectra of trace Xe and the He background.

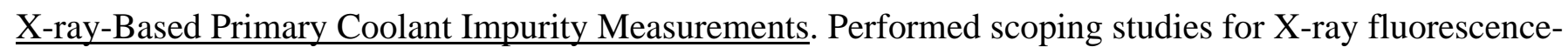
based (XRF) detector selection.

Experimental Vehicle for Out-of-Pile Testing. Adopted a three-level scaling analysis; first level will provide guidelines to vehicle design. Built a three-dimensional CFD model to assist with vehicle design. Calculated wall thickness for different vehicle materials and designs for the vehicle vessel.

\section{Rabbit System Capability Development}

\section{Technical Lead: David Wootan, PNNL}

\section{Partners: Texas A\&M}

- Prepared a draft presentation for the June 2020 Integration Meeting and conducted a dry run with the Technical Lead for Experiment Integration. 


\section{FY2020 May Status}

- Continued work on the in-situ sensors, neutronic streaming, thermal-hydraulic, and mechanical aspects of the VTR Rabbit.

- Delayed the schedule for putting the Rabbit proof-of-principle test in the water pool at Texas A\&M University reactor (NESC) until June 20 due to COVID-19 work restrictions.

- Participated in a meeting between VTR Experiments Technical Integration and DOE Office of Science Isotope Program on May 1, 2020, to discuss if/how the VTR could help the isotope program. The VTR rabbit was described and experience with the FFTF rabbit conceptual design was discussed. A follow-up meeting was tentatively planned for late-May or early-June.

\section{Upcoming Events:}

June 1, 2020, Deadline to submit design-build proposals

June 2, 2020, Project Management Risk Committee meeting

June 2 -3, 2020, Experiment Integration meeting

June 8 - 11, 2020, American Nuclear Society annual meeting

June 30, 2020, Energy Systems Acquisition Advisory Board meeting

July 14, 2020, VTR Quarterly Integration meeting 